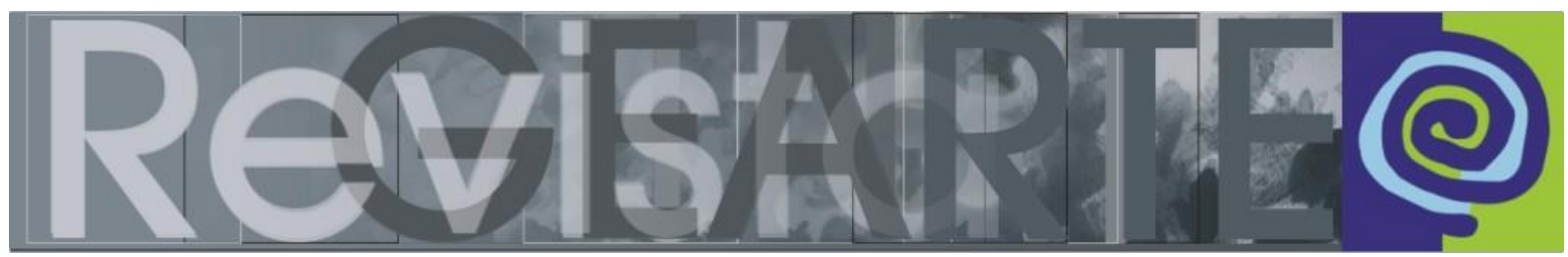

e-ISSN 2357-9854

\title{
Fanzines e visualidade, exercícios de autonomia e criação
}

\author{
Ana Basaglia (Universidade Anhembi-Morumbi - UAM, São Paulo/SP, Brasil)
}

RESUMO - Fanzines e visualidade, exercícios de autonomia e criação - Fanzines, publicações autorais produzidas de maneira artesanal e com baixo custo, são tradicionalmente celebrados por sua independência, tanto no aspecto comercial quanto em relação à visualidade, pois permitem ao seu editor misturar suas preferências pessoais a algumas regras de design. $O$ presente artigo pretende descrever o processo de produção de um fanzine dentro de um espaço escolar na cidade de São Paulo, após reflexões a respeito de alguns conceitos de design gráfico, alfabetismo e cultura visuais, autonomia - e apresentar algumas imagens produzidas pelos alunos.

PALAVRAS-CHAVE

Fanzine. Design gráfico. Educação. Alfabetismo visual. Autonomia.

ABSTRACT - Fanzines and visuality, exercises of autonomy and creation - Fanzines, authored publications produced in a low-cost way, have traditionally been celebrated for their independence, both commercially and visually, because it allows their publisher to mix their personal preferences with some design rules. The present paper aims to describe the process of producing a fanzine within a school space in the city of São Paulo, after reflections on some concepts of graphic design, literacy and visual culture, autonomy - and presents some images produced by students.

\section{KEYWORDS}

Fanzine. Graphic design. Education. Visual literacy. Autonomy.

\section{Introdução}

Em 2011, apresentei uma monografia na Fundação Armando Álvares Penteado (FAAP/SP) como trabalho de conclusão do curso de Pós-Graduação Lato Sensu em Design Gráfico, intitulada "Fundamentos do design gráfico aplicados no fanzine". 1 Nesse trabalho, expus o processo de confecção de um fanzine em uma escola municipal de São Paulo, feito por alunos de 11 a 13 anos, após refletirmos a respeito de alguns fundamentos do design gráfico. As relações imbricadas que visualizei desde então, entre imagens e design gráfico, alfabetização visual, educação e a possibilidade de manifestação autoral através dos fanzines e, mais recentemente, cultura visual, me levaram a querer aprofundar essa pesquisa, o que pude fazer

1 É possível consultar esse trabalho na biblioteca da FAAP/SP. 
durante o Mestrado cursado na Universidade Anhembi-Morumbi, em São Paulo. A pesquisa desenvolvida é mostrada parcialmente nesse artigo.

A contemporaneidade delineia um contexto marcado, sobretudo, pelas imagens. Nóbrega e Prado colaboram para esclarecer:

\begin{abstract}
Nossas retinas e nossos cérebros são invadidos por elas [as imagens] desde o instante em que saímos das cenas oníricas dos sonhos e desembarcamos na vigília de um novo dia. Vivemos sob o estímulo de imagens reproduzidas continuamente, seja nas páginas dos jornais e revistas ou na avassaladora miríade visual da internet, além das que produzimos em aparelhos que tornaram o instante fotográfico acessível a milhões de usuários, enquanto transitamos pela cidade moderna (NÓBREGA; PRADO, 2012, p. 8, grifo nosso).
\end{abstract}

Mas talvez muitos de nós estejamos acostumados, ou limitados, a lê-las de maneira superficial e até mesmo pueril ou, ainda, "como resultado de nossa incapacidade de ler essas imagens, nós aprendemos por meio delas inconscientemente" (BARBOSA, 2008, p. 19). Com a crescente influência da cultura visual na sociedade contemporânea, a educação nas artes visuais e através das artes visuais - e também a educação em design e por meio do design -, se faz necessária para respaldar as escolhas das pessoas, ajudando-as a criticar e propor ideias conectadas com a cultura visual e seus significados.

Considerando design gráfico como uma especialidade da área do design, fazer um resumo sobre o significado desse termo é sempre um exercício de escolha, visto que ele não possui um conceito único, nem pode ser considerado evento de evolução linear na nossa história. Cardoso (2010) nos lembra que o estudo da história do design é relativamente recente - os primeiros ensaios datam da década de 1920 -, mas a existência de ações ligadas ao design é muito anterior a esse período. Para ele, uma das principais características que distinguem o design como uma área do conhecimento humano é a fecundidade do diálogo entre verbal e visual.

A comunicação por meio de imagens e elementos visuais é denominada comunicação visual. Em sua forma mais básica, a alfabetização visual é a capacidade de entender o que está sendo visto em uma imagem (incluindo certas convenções, tais como profundidade e perspectiva). Indo mais além, a alfabetização visual pressupõe a compreensão da manipulação visual e a apreciação estética dos meios 
visuais e de comunicação. Para Dondis (1991, p. 230), "o alfabetismo significa a capacidade de expressar-se e compreender, e tanto a capacidade verbal quanto a visual pode ser apreendida por todos" - é importante ressaltar, no entanto, que o alfabetismo visual jamais poderá ser entendido como um sistema tão lógico e preciso quanto o é a linguagem verbal.

A necessidade de compreender melhor os termos que versam sobre visualidade nos levam ao conceito de cultura visual, que é muito amplo e cujo estudo requer um olhar aprofundado, não sendo o foco específico desse trabalho. Entretanto, não seria possível falar (ou justificar) o uso de fanzines como meio de expressão sem citar alguns pontos intrínsecos a essa expressão. Existem muitos estudos e vertentes, mas a definição de Barbosa (2011) parece ser a que melhor se adequa ao propósito dessa pesquisa. Segundo a autora, existem três principais linhas de cultura visual sendo estudadas a partir do ensino da Arte no Brasil, a saber: cultura visual excludente, cultura visual includente e contracultura visual. É essa terceira linha, ainda que contenha poucos adeptos entre nossos pesquisadores, que particularmente interessa para a minha reflexão, pois abomina o discurso verbal sobre a visualidade e procura exercer a crítica visualmente, entre outras falas entrelaçadas. O termo contracultura vai totalmente ao encontro do lugar que o fanzine parece ocupar na cultura ocidental contemporânea, se pensarmos nele como um "produto" que ora se apoia no verbal, ora se apoia no visual, e que questiona valores e práticas da cultura dominante da qual faz parte.

Fanzine costuma ser definido como uma publicação alternativa sem cunho comercial e geralmente amadora, de produção independente e de baixo custo, em que tesoura e cola costumam ser tão importantes quanto um programa de edição de textos ou uma copiadora (Magalhães, 1993). O fanzine também pode ser observado como objeto gráfico, cujas formas e processos D.I.Y. ${ }^{2}$ pelos quais é produzido, podem

2 Do inglês do it yourself (em português, faça você mesmo), refere-se à prática de fabricar ou reparar algo por conta própria em vez de comprar ou pagar por um trabalho profissional. A prática, atualmente, engloba qualquer área de atividade humana. A partir do final da década de 1970, o princípio faça você mesmo se tornou profundamente associado ao anarquismo e vários outros movimentos anticonsumistas, principalmente nos casos de grande e evidente rejeição à ideia de que um indivíduo deve sempre comprar de outras pessoas as coisas que deseja ou necessita. 
fornecer uma boa parcela de compreensão da história do design e da cultura popular que o cerca.

No Brasil a bibliografia a respeito do uso do fanzine pelo público infantil, em âmbito escolar ou fora dele, ainda é escassa. Seja pelo seu caráter anárquico, seja pela falta de estudo sobre esse assunto de um modo geral, fazer fanzine é encarado como uma atividade do "mundo alternativo", longe do dia a dia "normal" da maioria das pessoas e fonte não confiável de informação ou leitura. Paulatinamente os pesquisadores começam a reconhecer o potencial do fanzine como catalizador de um possível olhar sobre o cotidiano, possibilitando diferentes modos de atuação e inserção na sociedade.

Em âmbito educacional ou fora dele, fazer fanzine pode propiciar ao jovem o desenvolvimento de sua capacidade de pesquisar informações relevantes, de ter um olhar crítico sobre seu cotidiano e de produzir um material de comunicação que expressa suas ideias, unindo e enfatizando as relações entre textos verbais e visuais.

Falando em Educação, vale lembrar que o educador Paulo Freire (2014), um dos pensadores mais notáveis na história da Pedagogia, afirma que ensinar exige respeito aos saberes dos educandos; exige criticidade; exige estética e ética (decência e boniteza de mãos dadas); exige risco, aceitação do novo e rejeição a qualquer forma de discriminação; exige reflexão crítica sobre a prática docente; exige respeito à autonomia e à dignidade de cada um. Uma das tarefas mais importantes da prática educativa crítica é proporcionar as condições em que os educandos, em suas relações uns com os outros e todos com o professor, ensaiam a experiência profunda de:

\footnotetext{
Assumir-se como ser social e histórico, como ser pensante, comunicante, transformador, criador, realizador de sonhos, capaz de ter raiva porque capaz de amar. Assumir-se como sujeito porque capaz de reconhecer-se como objeto (FREIRE, 2014, p. 42).
}

A partir dessas concepções a leitura de mundo freireana ganha contornos especiais: é através dela que o sujeito pode firmar-se com autonomia e capacidade de autoria. Acreditamos que seja, portanto, no diálogo e no encontro entre esses 
saberes e conhecimentos que o fanzine pode atuar e ser relevante dentro do espaço escolar.

Com relação a padrão de projeto gráfico, não há regras preestabelecidas para se produzir um fanzine; ainda assim, a definição dos espaços a serem preenchidos demanda atenção, leituras, discussões entre os membros da equipe e escolhas. Dessa forma, trabalhar com fanzine permite que o jovem assuma seu papel de sujeito na construção de seus valores éticos e estéticos, pois o produto final corresponde "ao aprendizado e aos avanços pessoais que se conseguiu adquirir no decorrer do processo" (GALVÃO, 2010, p. 89).

"Fanzines são objetos gráficos pessoais, organizam significados através de sua forma e conteúdo, mas ao mesmo tempo funcionam para se comunicar", declara a designer gráfica e pesquisadora inglesa Teal Triggs em entrevista a Steven Heller. ${ }^{3}$

O pesquisador e designer norte-americano Michael Rock (apud TRIGGS, 2010) propôs que o objeto gráfico como forma poderia ser considerado uma espécie de "texto em si", ou seja, os próprios princípios do design (como tipografia, linha, forma, cor, contraste, escala etc.) se tornaram instrumentos através dos quais uma história pode ser contada. Isso traz à tona caminhos para compreender não só "o quê" o objeto gráfico significa, mas também "como" ele significa.

Tal abordagem pode ser aplicada aos estudos dos fanzines; o sentido é construído não somente através de imagens visuais, mas também através da relação simbiótica entre texto, imagem e forma gráfica própria. Coletivamente, esses elementos comunicam ideias e temas; sutilmente também comunicam as atitudes, opiniões e crenças dos seus leitores: os fanzines dizem respeito à cultura popular como um todo.

Diante dessas articulações, a pesquisa teve como objeto de estudo investigar as potencialidades da produção de fanzines como meio de expressão de criatividade - usando como base as artes elaboradas por crianças e adolescentes dentro do

3 Cf. artigo publicado no site do The New York Times, em 18 fev. 2011 e, posteriormente, impresso no jornal em 20 fev. 2011. 
espaço escolar, após reflexões compartilhadas a respeito de conceitos de design gráfico, alfabetismo visual, leitura de imagens, autonomia e cultura visual.

O objetivo era verificar:

- se o trabalho com fanzines permitia que os estudantes assumissem seu papel de sujeitos no processo de compreensão e construção de valores;

- se, ao mesmo tempo em que os fanzines organizam significados através de sua forma e conteúdo, eles seriam objetos gráficos extremamente pessoais e se prestariam a estabelecer comunicação de maneira autêntica e original com o meio social onde estão inseridos;

- se o design gráfico poderia se tornar uma potente ferramenta de comunicação e auxiliar crianças (cuja opinião, comumente, é considerada irrelevante) a terem voz mais ativa e a serem produtoras de sua própria cultura.

Da compreensão dos diversos conceitos pertinentes a esse objeto de estudo, passando pela observação do processo de confecção de fanzines, o trabalho permitiu um olhar mais atento para as questões (de design, de visualidade, de autonomia) que envolveram a criação e produção de um impresso gráfico especial que não visa lucro, que estimula a apropriação de novos paradigmas (especialmente na esfera da troca possível entre professores e alunos), e que foi, sobretudo, um espaço de experimentação coletiva, nesses tempos de domínio dos computadores.

\section{A EMEF Amorim Lima}

Os trabalhos mostrados nesse artigo foram feitos na Escola Municipal de Ensino Fundamental (EMEF) Desembargador Amorim Lima, situada no bairro do Butantã, na zona oeste da cidade de São Paulo/SP, e que tem um projeto políticopedagógico autônomo e único, voltado para as demandas e necessidades de sua comunidade. Dentro desse projeto, a escola promove oficinas especiais, elaboradas em parceria com diversos voluntários, e uma dessas oficinas foi a Oficina de jornal, proposta por uma jornalista. 
Com encontros semanais, a presença era facultativa e a turma composta majoritariamente por alunos com idades entre 12 e 13 anos, apesar da escola contar com crianças e adolescentes de 6 a 15 anos. Em 2009, a Oficina de jornal produziu e publicou uma única edição desse jornal; já em 2010, produziu e publicou mais dois números, dessa vez, editorados por uma designer gráfica. Essas edições foram consideradas pela escola um avanço sob o aspecto visual, visto que a primeira publicação foi montada pela própria jornalista, pouco acostumada com os programas de edição existentes.

O objetivo da coordenação pedagógica da escola com o projeto da Oficina de jornal sempre transitou pelo viés apontado no artigo de Alves e Ramo (1995): produção de material crítico, voltado para a realidade que cerca os alunos da escola. Mas na hora de divulgar (diagramar, imprimir e distribuir) os textos produzidos pelas crianças, a forma como isso estava sendo feito incidia em um modo tradicional e conservador, de acordo apenas com o que os adultos entendiam que deveria ser. Por dois anos, pouco se questionou a respeito desse jeito tradicional e pouco expressivo de lidar com a produção das crianças - simplesmente se determinava um estilo de comunicação visual, baseado em gostos e preceitos adultos, e assim os jornais eram impressos e distribuídos.

Em 2011, com a mudança de coordenação da oficina, surgiu a oportunidade de se pensar em outras formas de divulgação dessa produção. Dentre as muitas considerações que possibilitaram essa proposta, uma das mais fortes foi a crença na capacidade crítica das crianças como fazedoras e leitoras de seu próprio veículo de comunicação.

Assim, a Oficina de jornal foi transformada em Oficina de fanzine e o grupo de alunos passou a produzir novas edições do agora rebatizado "Fanzirim", o fanzine do Amorim. Para dar conta dessa passagem, oficinas de produção e rodas de conversas foram oferecidas aos alunos, para que o grupo pudesse entender a proposta e produzir seus próprios materiais. 


\section{A oficina de fanzine na EMEF Amorim Lima}

Os encontros com a turma do Jornal do Amorim aconteceram uma vez por semana, com duração de aproximadamente uma hora e meia, geralmente na biblioteca da escola.

A descrição não segue uma cronologia rigorosa (apesar de todos os encontros terem sido registrados dia após dia), porque a construção desse fazer também foi um pouco caótica, aliás, como é a construção de todo fanzine: ora conversávamos sobre algum conceito, ora fazíamos um exercício prático, ora olhávamos para soluções gráficas publicadas em livros, revistas, jornais e impressos em geral, ora refletíamos sobre as possibilidades ao nosso alcance.

Decidida a mudança de jornal para fanzine, lancei a pergunta aos alunos: "Todos vocês sabem o que é um fanzine?". Levei, para cada criança, um breve resumo da definição de fanzine, impresso em papel colorido, e conversamos em roda. Mostrei para os alunos uma coletânea sobre fanzines para que eles entendessem melhor o que iríamos fazer. O livro de Triggs (2010) reúne mais de 750 imagens de fanzines, impressos em cerca de 250 páginas e organizados em 6 grandes capítulos temáticos, de fanzines de 1940 a e-zines do século XXI. As crianças compreenderam melhor a proposta; elas continuaram produzindo textos para o jornal/fanzine.

Quando já estava um pouco mais evidente o que a "nova" oficina se propunha e o envolvimento que essa mudança implicava, introduzi um exercício prático, que podia ser feito por duplas ou pequenos grupos de alunos. Levei e entreguei para todos uma folhinha (1/4 de um sulfite A4) impressa na frente e no verso. De um lado, o poema "Dentro do livro", do escritor e ilustrador de textos infantis Ricardo Azevedo; ${ }^{4}$ do outro, a instrução da atividade - recontar um trecho do poema, usando linguagem não verbal, procurando ressaltar algum elemento básico da comunicação visual.

4 Azevedo, R. Dezenove poemas desengonçados. São Paulo: Ática, 1999, 56p. A escolha desse texto, dentre tantos possíveis, se deu por um objetivo específico: ele possibilita uma ampla gama de respostas, com seus muitos substantivos concretos e abstratos. Além disso, o texto relata com delicadeza a atividade da leitura - e a leitura (em seus vários níveis possíveis) é importante para a reflexão proposta pela oficina. 
As crianças poderiam escolher qualquer trecho e qualquer elemento previamente conversado (ponto, linha, cor, textura etc.), e usariam a colagem como técnica. No encontro seguinte, distribuí o mesmo poema, mas o exercício foi outro: usando recursos de linguagem verbal, recontar algum trecho do poema; a técnica seria a escrita com canetinhas ou lápis colorido. O objetivo era verificar como as crianças lidariam com o mesmo texto, mas com proposta distinta do encontro anterior.

Em alguns encontros, para mudar um pouco a dinâmica dos exercícios práticos, pedia que eles fossem feitos individualmente. "O texto como imagem, a imagem como texto", esse era o título de dois dos exercícios propostos: a partir do mesmo poema trabalhado nos encontros anteriores, cada criança deveria criar cinco imagens, usando apenas letras; depois, cada uma deveria escrever uma palavra, relacionada com o fanzine a ser produzido, ressaltando um recurso de comunicação visual. E sempre, entre uma conversa e outra, eu apresentava aos alunos alguns conceitos de linguagem visual, alguns alicerces e princípios de design.

Logo os alunos se mostraram empolgados e animados com os temas abordados e com o corte-recorte-e-cole, e alguns já estavam trazendo seu próprio material de casa. As propostas sempre estreitavam o objetivo de fazer os alunos perceberem as infinitas possibilidades que eles possuem para comunicar o que quiserem.

\section{Análise da prática}

Apresentamos a seguir algumas imagens, dentre as coletadas durante os encontros, aglutinadas em três grandes grupos, tendo como orientação os critérios definidos pelas designers e professoras Ellen Lupton e Jennifer Phillips (2008, p. 8) para o design gráfico: 1) "alicerces do design" (ponto, plano, linha); 2) "princípios" (escala, movimento, ritmo, equilíbrio, textura, cor, figura/fundo); e 3) os "conceitos universais em ascensão" (transparência, camada, enquadramento, hierarquia, modularidade, grid, padronagem, diagrama). Lupton, comentando o pós-modernismo, lembra-nos da rejeição à comunicação universal, argumentando que é inútil buscar significado inerente a uma imagem ou objeto isoladamente, pois as pessoas trarão 
seus próprios preconceitos culturais e suas experiências pessoais ao processo de interpretação.

Algumas dessas produções foram usadas pelos estudantes como arte-final no fanzine; outras representam os exercícios propostos, para que pudessem refletir a respeito de suas produções. Não pretendemos classificar os trabalhos apresentados com rigidez e restrição a um único conceito, ou mesmo com rigor profissional (posto que os alunos não são designers); a proposta foi relacionar a produção feita pelos alunos com alguns dos princípios que norteiam o entendimento do design gráfico atual, levando em conta suas características de fluidez, mutação e pluralidade, anteriormente mencionados.

\section{Grupo 1 - Alicerces do design: ponto, linha, plano}

O ponto, a linha e o plano compõem os alicerces do design (LUPTON; PHILLIPS, 2008, p. 13). Partindo desses elementos, é possível criar imagens, ícones, texturas, padrões, diagramas, animações, sistemas tipográficos etc.

Figura 1 - Imagens com ponto, linha, plano

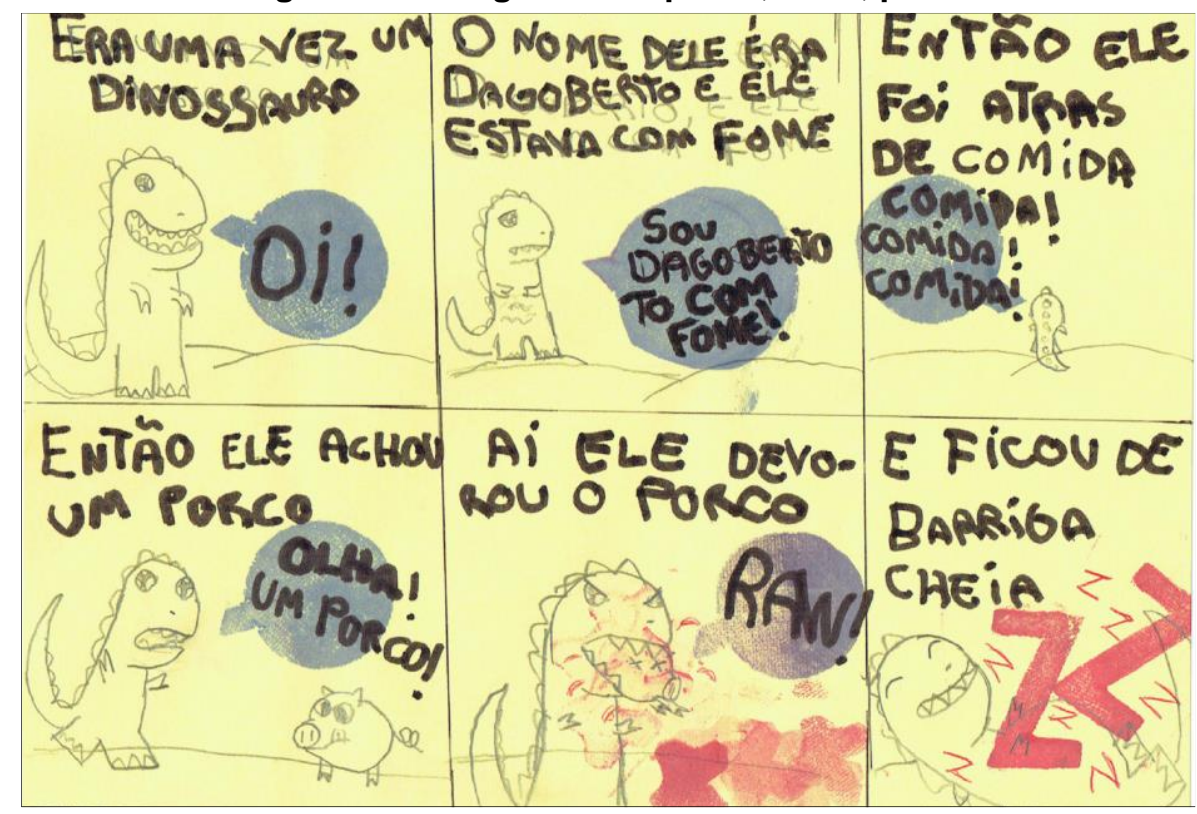




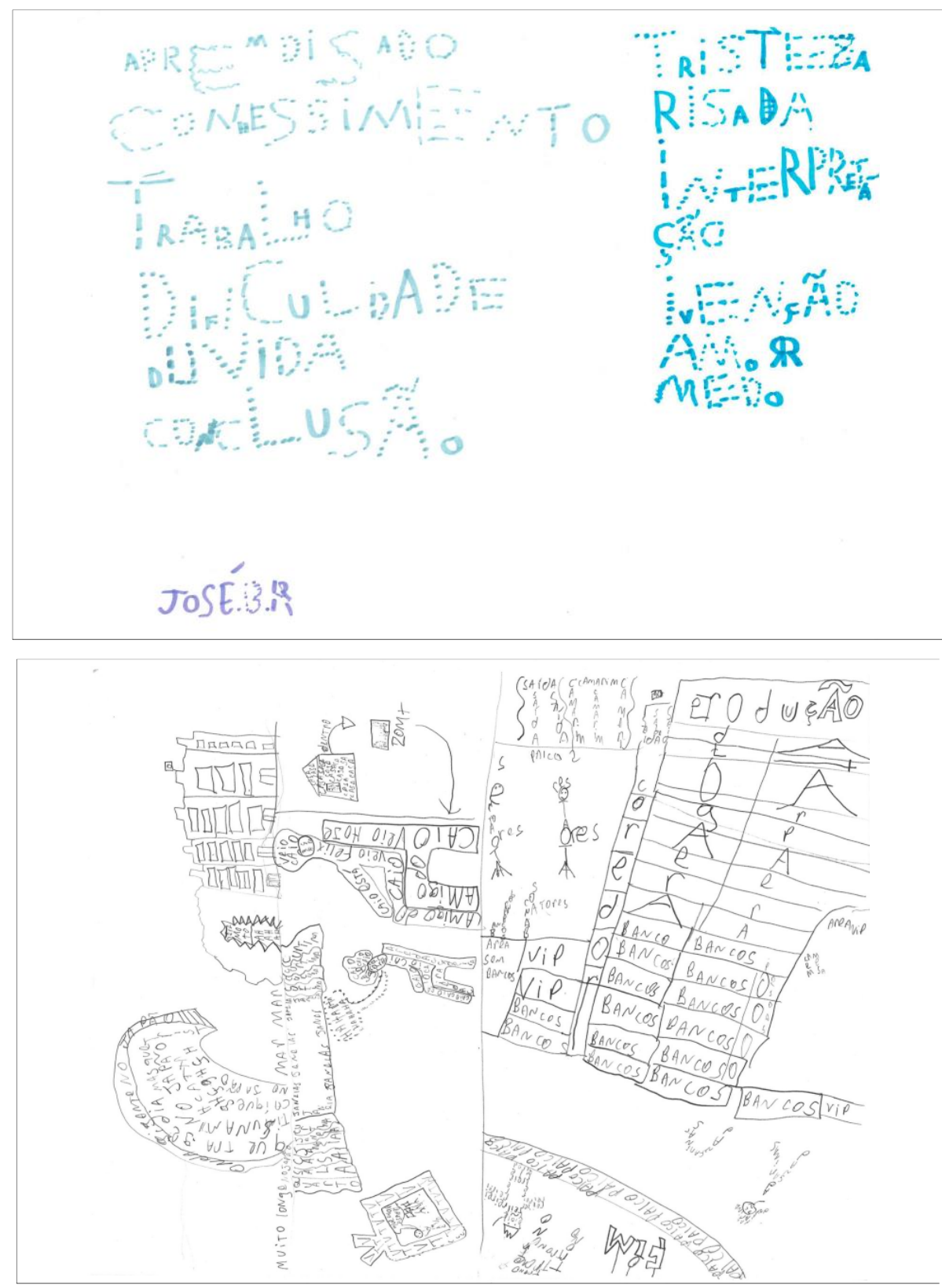

Fonte: arquivo da autora.

Grupo 2: Princípios: escala, movimento, ritmo, equilíbrio, textura, cor, figura/fundo

Textos recentes de design têm revisitado a Bauhaus para falar desses princípios no design, ainda que atualmente se reconheça a diferença entre descrever e interpretar essa linguagem, evitando um "significado universal". Todos esses conceitos misturam-se e sobrepõem-se, concentram-se em aspectos particulares da comunicação visual, respondem com força à intenção de comunicação e constroem relações de criatividade. 
Figura 2
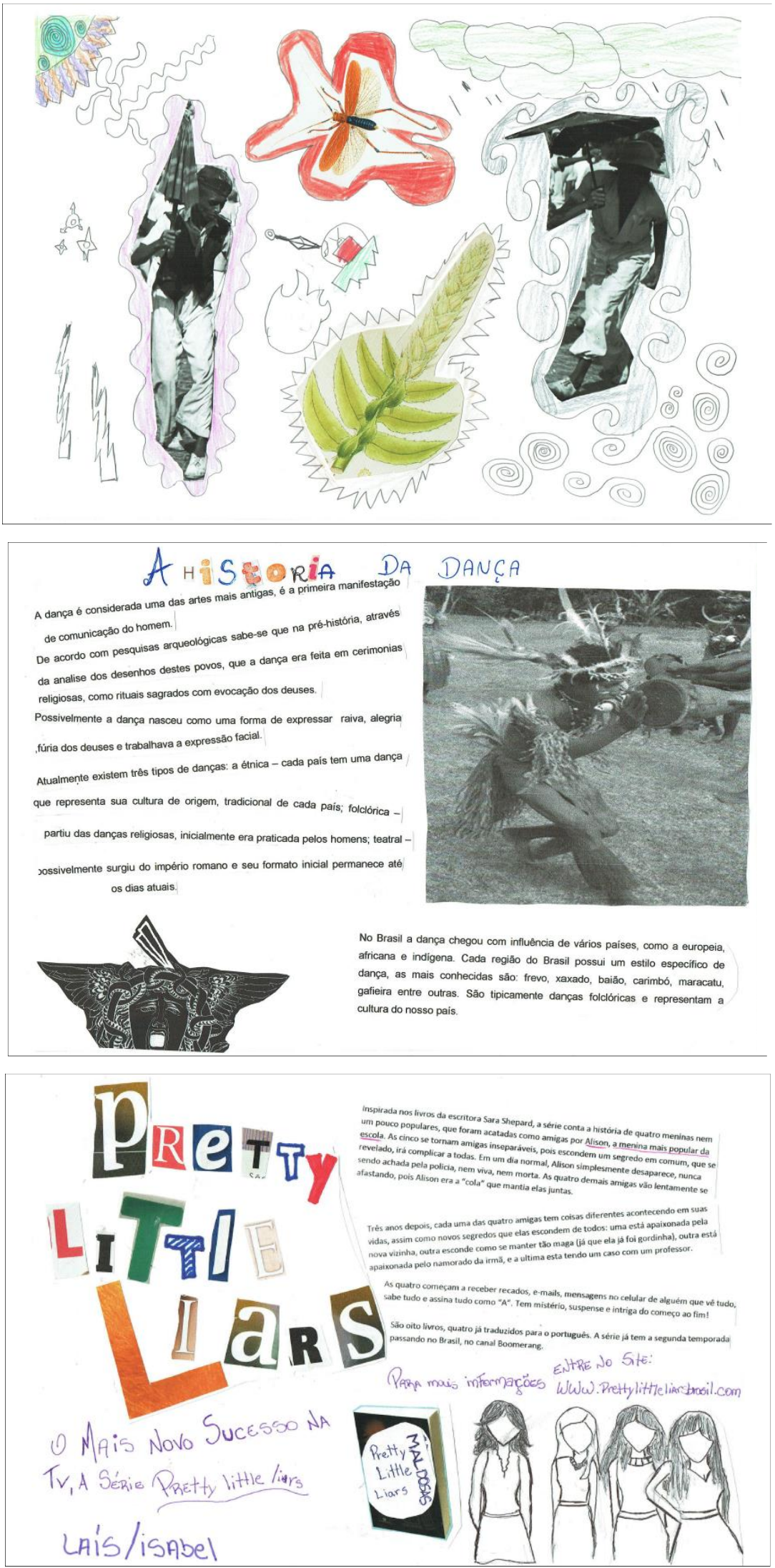

Fonte: arquivo da autora. 
Grupo 3: Conceitos universais em ascensão: transparência, camada, enquadramento, hierarquia, modularidade, grid, padronagem, diagrama

Podemos nos perguntar: o que é realmente novo no design elementar? A transparência e a camada, por exemplo, são conceitos importantes e sempre estiveram em evidência nas artes gráficas, mas adquirem novos sentidos com a ascensão das mídias baseadas em movimento (TV, cinema), pois sua linguagem tornou-se praticamente universal. Novamente, os conceitos aqui podem se mesclar e ser justapostos, em relações criativas e cheias de significado.

Figura 3- Mescla de conceitos

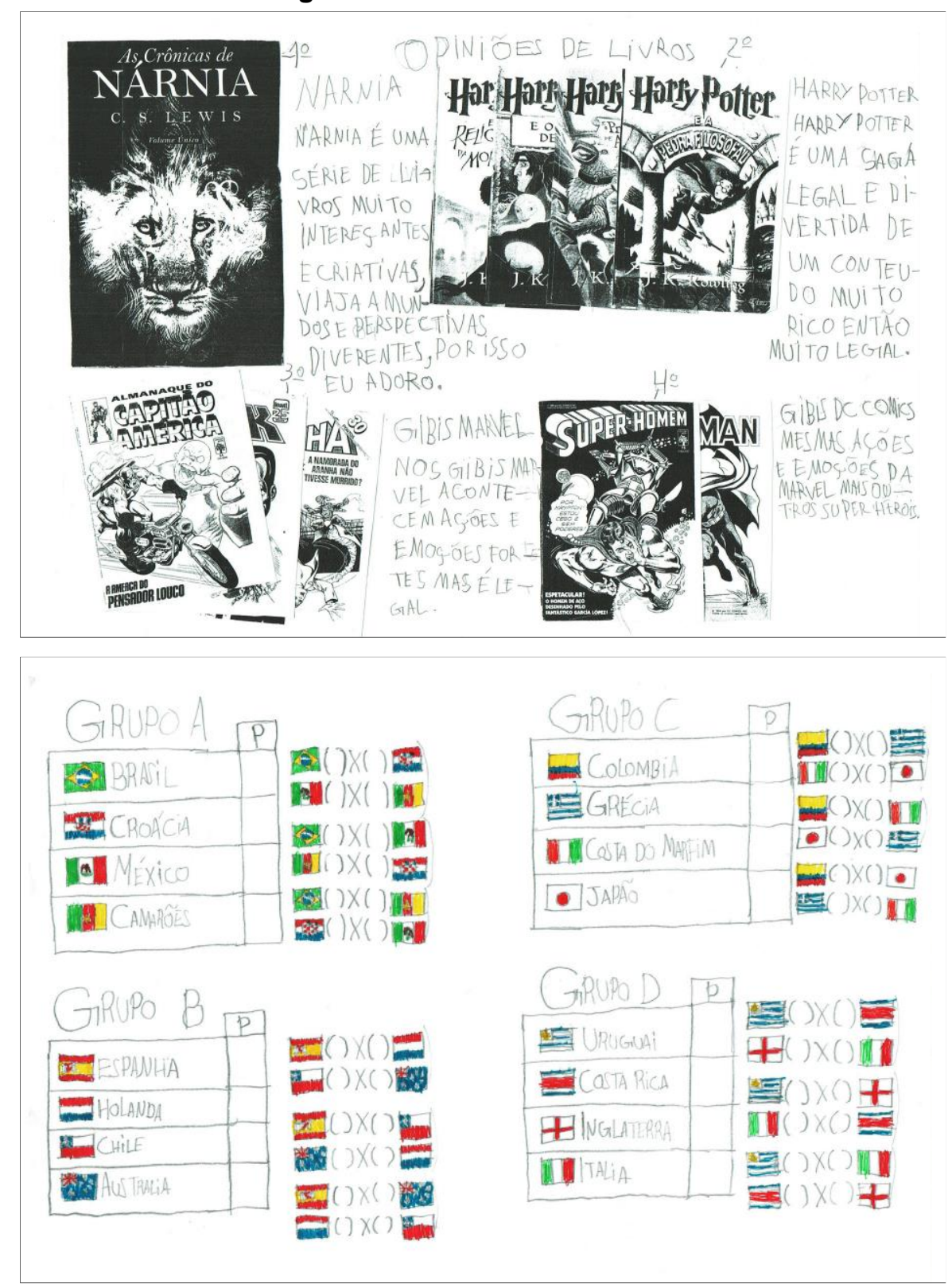




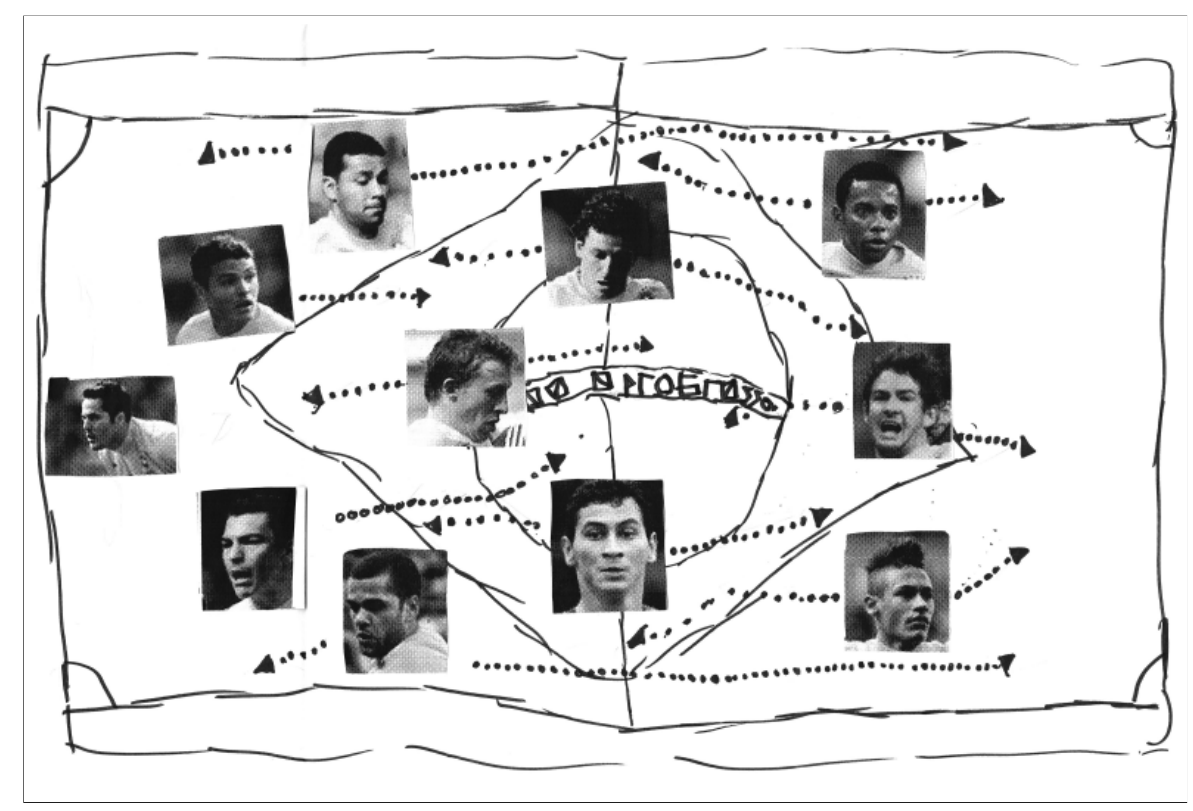

Fonte: arquivo da autora.

\section{Conclusão}

A EMEF Desembargador Amorim Lima é uma escola cujo projeto políticopedagógico permite que se proponha atividades diferenciadas como a Oficina de fanzine. Ao possibilitar que seus alunos vivenciem uma oficina que thes oferece autonomia na produção de imagens e textos críticos, voltados para sua realidade, a escola se mostra plural e respeitosa com a vontade e a necessidade de expressão desses alunos.

O alfabetismo visual precisa ser uma preocupação prática de qualquer educador: através dele, todos se transformam em observadores menos passivos, colocando-se acima dos modismos e fazendo seus próprios juízos de valor a respeito do que consideram apropriado e esteticamente agradável. Como potente ferramenta de comunicação que é (e sem a necessidade de "amarras" impostas por definições predeterminadas, como é praticado atualmente), o design pode ajudar as crianças a terem uma voz mais ativa e a se expressarem de modo autêntico e verdadeiro, de maneira instantânea, flexível e plural.

Através da reflexão e do (re)conhecimento de fundamentos de comunicação visual nos encontros de fanzine na EMEF Amorim Lima, pudemos produzir um 
material reflexivo e autoral, respeitando a diversidade dos diversos atores presentes, contribuindo para a formação de pessoas reflexivas, críticas, criativas e colaborativas.

\section{Referências}

ALVES, Januária Cristina; RAMO, Regina Mara. O jornal infantil: criticar e produzir. Comunicação e educação. São Paulo, n. 2, p. 106-115, jan./abr. 1995. Disponível em: <http://www.revistas.usp.br/ comueduc/article/viewFile/36143/38863>. Acesso em: 10 jul. 2017.

AZEVEDO, Ricardo. Dezenove poemas desengonçados. São Paulo: Ática, 1999. 56p. Disponível em: $<$ http://www.ricardoazevedo.com.br/livro/poema-do-livro-dezenove-poemas-desengoncados/>. Acesso em: 10jul. 2017.

BARBOSA, Ana Mae (Org.). Inquietações e mudanças no ensino da arte. São Paulo: Cortez, 2008.

BARBOSA, Ana Mae. A cultura visual antes da cultura visual. Educação, Porto Alegre, v.34, n. 3, p. 293-301, set./dez. 2011.

CARDOSO, Rafael. Uma introdução à história do design. São Paulo: Blucher, 2010.

DONDIS, Donis A. Sintaxe da linguagem visual. São Paulo: Martins Fontes, 1991.

FREIRE, Paulo. Pedagogia da autonomia: saberes necessários à prática educativa. São Paulo: Paz \& Terra, 2014.

GALVÃO, Demetrios Gomes. Ressonâncias no meio do caminho e/ou no caminho do meio: a poética infame dos fanzines. In: MUNIZ, Cellina Rodrigues (Org.). Fanzines: autoria, subjetividade e invenção de si. Fortaleza: Edições UFC, 2010.

HELLER, Steven. Irreverence you can almost touch. The New York Times, Nova York, 18 fev. 2011. Sunday Book Review: Visuals. Disponível em: <http://www.nytimes.com/2011/02/20/ books/review/Heller-t.html>. Acesso em: 10 jul. 2017.

LUPTON, Ellen; PHILLIPS, Jennifer Cole Phillips. Novos fundamentos do design. São Paulo: Cosac Naify, 2008.

MAGALHÃES, Henrique. O que é fanzine. São Paulo: Editora Brasiliense, 1993.

NÓBREGA, Maria José; PRADO, Ricardo. Como eu ensino: leitura de imagens. In: SANTAELLA, Lucia. Leitura de imagens. São Paulo: Melhoramentos, 2012.

TRIGGS, Teal. Fanzines. United Kingdom: Thames \& Hudson, 2010.

\section{Ana Basaglia}

Possui graduação em Desenho Industrial pela Fundação Armando Álvares Penteado (1988), graduação em Comunicação Visual pela Fundação Armando Álvares Penteado (1989), especialização em Design Gráfico pela Fundação Armando Álvares Penteado (2011), mestrado em Design pela Universidade Anhembi Morumbi (2016), sob a orientação da professora Ana Mae Barbosa. A monografia da especialização foi exposta no Museu da Casa Brasileira em 2012, por ocasião do 26을 Prêmio Design MCB. Atua em estúdio próprio de Design Gráfico, desenvolvendo projetos gráficos nas áreas correspondentes. Ganhou o 2ํ lugar do Prêmio Jabuti-2007 de Projeto Gráfico, com mais dois parceiros.

E-mail: ana.basaglia@gmail.com

Currículo: http://lattes.cnpq.br/2194030056408897

Recebido em 15 de julho de 2017 Aceito em 23 de novembro de 2017 